BMJ Open Sport \& Exercise Medicine

\title{
Prevention of musculoskeletal injuries in recreational field hockey: the systematic development of an intervention and its feasibility
}

\author{
Vincent Gouttebarge, ${ }^{1,2,3,4}$ Victor Zuidema
}

\begin{abstract}
To cite: Gouttebarge V, Zuidema V. Prevention of musculoskeletal injuries in recreational field hockey: the systematic development of an intervention and its feasibility. BMJ Open Sport \& Exercise Medicine 2018;4:e000425. doi:10.1136/ bmjsem-2018-000425
\end{abstract}

Accepted 4 September 2018

\section{Check for updates}

\section{(C) Author(s) (or their} employer(s)) 2018. Re-use permitted under CC BY-NC. No commercial re-use. See rights and permissions. Published by BMJ.

${ }^{1}$ Dutch Consumer Safety Institute, Amsterdam, The Netherlands

${ }^{2}$ Department of Orthopaedic Surgery, Amsterdam Movement Sciences, Amsterdam UMC, University of Amsterdam, Amsterdam, The Netherlands ${ }^{3}$ Amsterdam Collaboration on Health \& Safety in Sports (ACHSS), AMC/VUmc IOC Research Center, Amsterdam, The Netherlands

${ }^{4}$ Division of Exercise Science and Sports Medicine, University of Cape Town, Cape Town, South Africa

Correspondence to Dr Vincent Gouttebarge; v. gouttebarge@amc.uva.nl

\section{ABSTRACT}

Objective This article describes the systematic development of an intervention for the prevention of lower extremity injuries in field hockey and the assessment of its feasibility.

Methods The intervention was developed according to the first four steps of the intervention mapping and knowledge transfer scheme processes, mostly based on focus group interviews with experts in field hockey and injury prevention (needs assessment; objective and target groups; content selection; development). Subsequently, a quasi-experimental research (one-group post-test design) was conducted among 35 young field hockey players and 7 coaches. Participants were asked to use the intervention for 3 weeks, and the degrees of relevancy, suitability, satisfaction and usability of the intervention were assessed by means of a questionnaire and a group interview. Results First, the needs assessment conducted among the main actors within recreational field hockey revealed that an injury prevention intervention was needed, ideally delivered through videos via an application for smartphone/tablet or website. Second, the objective and target groups of the intervention were defined, namely to prevent or reduce the occurrence of lower extremity injuries among both young and adult recreational field hockey players. Third, warming-up exercises were selected as preventive measures and strategies (eg, core stability, strength, coordination). Last, the 'Warming-Up Hockey' intervention was developed, consisting of a warm-up programme (delivered by coaches including more than 50 unique exercises). The relevancy, satisfaction and usability of 'Warming-Up Hockey' were positively evaluated, but two main alterations were made: the duration of the 'Warmingup Hockey' was reduced from 16 to 12 min and a matchspecific warm-up was added.

Conclusion The feasibility of 'Warming-Up Hockey' was positively assessed by players and coaches. Prior to its nationwide implementation, the effectiveness of the intervention on injury reduction among field hockey players should be conducted.

\section{INTRODUCTION}

Field hockey is a popular team sports in the world, especially in the Netherlands, with more than 250000 registered young and
What are the new findings?

- Based on two structured and systematic processes the 'Warming-Up Hockey' intervention was developed in order to prevent or reduce the occurrence of lower extremity injuries (especially knee and ankle injuries) among both young and adult recreational field hockey players.

- Being available through a website and application for smartphone/tablet, the 'Warming-Up Hockey' intervention is a warm-up programme (12 min) including more than 50 unique exercises that has to be used at least twice a week prior to any field hockey.

- Both field hockey players and coaches were overall positive about the exercises of the 'Warming-Up Hockey' intervention.

adult players. ${ }^{1}$ While field hockey, like other sports, is beneficial to physical, mental and social well-being, it is also associated with a risk for musculoskeletal injuries. ${ }^{2-4}$ The number of injuries per 1000 player match hours ranged from 29 in women to 48 in men, occurring commonly in the head, face, thigh and knee. ${ }^{2}$ Among collegiate women field hockey players, injury rates calculated over 15 years ranged from 3.7 (practice) to 7.9 (match) injuries per 1000 athlete exposures, with up to $60 \%$ of these injuries occurring in the lower extremities. ${ }^{3}$ In the Netherlands, similar incidence rates are reported annually among young and adult recreational field hockey players, rising to 4.1 injuries per 1000 playing hours in 2012. ${ }^{4}$ Being mostly acute, musculoskeletal injuries in field hockey occur principally in the knees $(23 \%)$ and ankles $(20 \%){ }^{4}$ These injuries lead to substantial direct and indirect healthcare costs, as they are also likely to induce impairments in daily life, sport and/or work. ${ }^{4}$

With regard to the incidence of musculoskeletal injuries among young and adult field hockey players and their negative consequences and societal impact, one might 
expect effective preventive measures to be available, especially for the common lower extremity injuries. However, no measures focusing on the prevention of lower extremity injuries in recreational field hockey exist in the Netherlands. Consequently, a research project has been ongoing in the Netherlands in order to develop and implement an intervention to prevent the occurrence of lower extremity injuries among young and adult recreational field hockey players. In this article, the systematic development of an intervention is presented, as well as the assessment of its feasibility in young recreational field hockey teams.

\section{METHODS}

\section{The systematic development of the intervention}

Relying on four subsequent steps, the intervention mapping (IM) and knowledge transfer scheme (KTS) are two structured and systematic processes often used in the Netherlands for the development of interventions. ${ }^{5-7}$ Recently, these systematic processes were successfully applied in order to develop an intervention for the prevention of volleyball injuries. ${ }^{8}$ Therefore, the IM and KTS processes were followed in order to develop an intervention aimed at preventing lower extremity injuries among recreational young and adult field hockey players.

\section{Step 1: needs assessment}

The key aims of the needs assessment were (1) to assess the needs (content, form, behaviour) and support for the intervention; (2) to identify the objectives and target groups of the intervention; and (3) to discuss strategies for the future implementation of the intervention. To this end, two semistructured focus group interviews were held: one consisting of six recreational field hockey coaches and one with ten experts in the field of injury prevention (not exclusively related to field hockey). Each focus group interview took 4 hours (with three breaks of $10 \mathrm{~min}$ ) and was held in 2013 and 2014. Subsequently, an anonymous electronic survey (in Dutch) was set up and distributed in 2013 by the Royal Dutch Hockey Association (KNHB) to recreational field hockey players and coaches in order to explore whether the qualitative information gathered through the focus group interviews was largely supported. Questions were formulated in relation to, among others, (1) lower extremity injuries in field hockey; (2) current and future injury prevention behaviour in field hockey; (3) needs and support for the intervention; (4) characteristics (content, form) of the intervention; and (5) strategies to deliver the intervention.

\section{Step 2: objective and target group(s)}

Experts in injury prevention (strength and conditioning trainers, physical therapists, sports physicians) and field hockey (players, coaches, medical committee of the $\mathrm{KNHB}$ ) were approached in order to formulate clearly the objective of the intervention and to specify its target groups. Two multidisciplinary meetings (lasting 3 hours with two breaks of $10 \mathrm{~min}$ ) were held in 2014, during which the scientific literature on the incidence, prevalence, aetiology and preventive measures of injuries (field hockey-specific or not) was used.

\section{Step 3: selection of preventive measures and strategies}

Information gathered through the needs assessment (step 1) as well as findings from the scientific literature on the incidence, prevalence, aetiology and preventive measures of lower extremity injuries (field hockey-specific or not) (step 2) was used in order to select preventive measures (content) and strategies (form) for the intervention. To this end, a multidisciplinary expert meeting (lasting 4 hours with three breaks of $10 \mathrm{~min}$ ) with ten participants (physical therapists, sports physicians, field hockey, injury prevention) was held in 2014. Led by an experienced consultant, the experts' meeting was audiotaped and notes were taken. During the meeting, experts discussed the identified preventive measures, and consensus between experts was reached for the selection of preventive measures.

\section{Step 4: development of the 'Warming-Up Hockey'}

All information gathered in the previous steps was synthesised and translated for the development of the intervention. To this end, five work sessions with six experts in the field of field hockey and injury prevention (physical therapists, strength and conditioning trainers, representatives of the KNHB) were held. Led by an experienced consultant, each work session took 3-6 hours (with two to four breaks of $10 \mathrm{~min}$ ). The five work sessions were held in 2014.

\section{The feasibility of the intervention}

A quasi-experimental research (one-group post-test design) was conducted over a period of 3 weeks. ${ }^{9}$ The participants were healthy recreational young field hockey players and their coaches. Players needed to be (1) 8 years of age or older; (2) playing recreationally in a field hockey team; (3) training and/or competing at least twice a week; and (4) speaking Dutch fluently. Coaches needed to be (1) 16 years of age or older and (2) speaking and reading Dutch fluently. Since this is a 'feasibility study', a convenient sample of at least 30 field hockey players was intended to be recruited. ${ }^{9}$

For each exercise within the intervention, the following outcomes were measured: (1) degree of relevancy and added value of the exercises; (2) degree of suitability of the exercises within training sessions; (3) degree of satisfaction about the instructions of the exercises; and (4) degree of usability of the exercises. To this end, questions were formulated, such as the following: 'Is this exercise relevant and of added value within the warm-up of field hockey players?' 'Are the instructions for this exercise clear and complete?' 'Can this exercise be performed by field hockey players?' All outcomes measures were measured on a 5-point scale (from 'completely disagree' to 'completely agree') and embedded within a 
questionnaire (for coaches) and an interview form (for players and coaches).

Players, their parents and their coaches were informed by the KNHB by email about the intervention and related feasibility study (aim and procedures). If willing to participate voluntarily in the study, parents of the players and coaches signed an informed consent. The different weekly warm-up programmes (and related exercises) were divided across the different teams, and players and their coaches were asked to use a new weekly warm-up programme at every session (training or competition) during a period of 3 weeks. After the use of a new warm-up programme, coaches were asked to complete a paper questionnaire including all outcome measures under study. After the period of 3 weeks, a semistructured faceto-face group interview (10 min) was held in each club with players and their coaches about the feasibility of the intervention. All quantitative data were entered in the statistical software IBM SPSS Statistics V.23.0 for Windows and descriptive data analyses were conducted for each outcome and group of exercises. A content analysis of the qualitative data was conducted (coding, categorising and summarising the data) in order to present a valid synthesis of participants' view on the feasibility of the intervention.

\section{RESULTS}

\section{The systematic development of the intervention}

Step 1: needs assessment

Information collected through the two focus group interviews indicated that (1) lower extremity injuries were indeed common among young and adult recreational field hockey players; (2) support measures or interventions focusing on the prevention of lower extremity injuries were lacking in recreational field hockey; (3) there was a need for an injury prevention intervention for both young and adult recreational field hockey players; (4) an injury prevention intervention could be delivered by coaches and embedded prior to a field hockey activity (training or match) within the warm-up; and (5) information and instructions related to the injury prevention intervention should not be presented on paper but be delivered as videos through an application for smartphone/tablet and/or website. The electronic survey completed by 269 field hockey players (32\% response rate) and coaches (68\%) confirmed the information collected through the two focus group interviews. The main outcomes of the survey are presented in box 1 .

\section{Step 2: objective and target group(s)}

Based on the meetings, the following intervention objective and target groups were formulated, namely to prevent or reduce the occurrence of lower extremity injuries (especially knee and ankle injuries) among both young and adult recreational field hockey players.
Box 1 Needs assessment for an injury prevention intervention in field hockey

Injuries in recreational field hockey.

- Respondents suggested that $80 \%$ of the injuries occurring in field hockey are directed towards the lower extremities.

\section{Current and future injury prevention knowledge and} behaviour.

- $79 \%$ of the respondents mentioned that there was no or too little attention given to injury prevention in field hockey clubs.

- $61 \%$ of the field hockey coaches stated that they do not give any advice on injury prevention to their players.

- $55 \%$ of the field hockey coaches assessed their knowledge towards injury prevention as either insufficient or very insufficient.

- $43 \%$ of the field hockey coaches stated that they would like to have a proactive role towards injury prevention.

- $88 \%$ of the respondents stated that injury prevention was the responsibility of the players.

- $56 \%$ of the respondents stated that injury prevention was the responsibility of the coaches.

The future injury prevention intervention.

- $75 \%$ of the respondents mentioned that the intervention for young and adult recreational field hockey players should be embedded within the warm-up prior to a field hockey activity (training or match).

$86 \%$ of the respondents stated that field hockey coaches should provide information and instruction in order to reduce injuries.

\section{Step 3: selection of preventive measures and strategies}

Experts identified several preventive measures (content) directed towards the modifiable risk factors of lower extremities injuries. The key preventive measures and strategies selected by the experts for the prevention of lower extremity injuries were related to core stability, strength, coordination and balance, and mobility, that is, flexibility. ${ }^{10-24}$ In accordance to the needs of field hockey players and coaches, experts agreed that all selected preventive measures (content) should be embedded within the warm-up prior to a field hockey activity (training or match) and made available through a website and an application for smartphone/tablet.

\section{Step 4: development of the 'Warming-Up Hockey'}

The 'Warming-Up Hockey' intervention (available in Dutch) consists of a warm-up programme including more than 50 unique exercises (with different variations and levels for young and adult players) that has to be used at least twice a week prior to any field hockey activity (training or match). Each warm-up programme lasts 16 min and is divided into (1) preparation phase as a cardiovascular warm-up (4 min); (2) field hockey technical skills (4 min); (3) movement skills (4 min); and (4) field hockey tactical skills $(4 \mathrm{~min})$. All exercises are gender-specific and age-specific (8-9 years, $10-11$ years, $12-15$ years, $16+$ years $)$. The intervention provides a new programme to field hockey coaches every week for a whole season, showing progressive increments in terms of intensity, frequency, duration and/or complexity. Information and 
instructions about the exercises are available as texts and videos (including voiceover). Warming-Up Hockey and related exercises are embedded into a website and an application for smartphone/tablet (automatic synchronisation between devices and platforms). Due to practical reasons, the intervention was made available first on paper for the feasibility study, with a thorough description (including pictures) of all exercises and face-to-face instructions provided to the coaches.

\section{The feasibility of the intervention}

In total, 35 field hockey players and 7 coaches from three different clubs were enrolled in the study. Overall, coaches were positive towards all groups of exercises within 'Warming-Up Hockey'. Six out of seven coaches assessed the relevancy, satisfaction and usability of 'Warming-Up Hockey' very positively, while one coach remained neutral. The suitability of the exercises was mainly scored as neutral. The group interviews among players and coaches confirmed that players and coaches were very pleased with the phases, themes and exercises of the intervention. The group interviews also revealed that 'Warming-Up Hockey' was too time-consuming to be optimally embedded within a regular training session. Players and coaches mentioned that 'Warming-Up Hockey' could not be used before matches: hockey matches at recreational level are played after each other over a whole day, which means that hockey pitches are not able to be used prior to a match to perform a lengthy warming-up. Furthermore, the players and coaches mentioned during the interviews that videos and texts describing the Warming-Up Hockey' exercises were essential to ensure optimal execution, ideally being made available through a website and an application for smartphone/tablet.

\section{DISCUSSION}

This article aimed to describe (1) the systematic development and (2) the assessment of the feasibility of an intervention aiming to prevent or reduce the occurrence of lower extremity injuries among young and adult recreational field hockey players. The systematic development of the intervention was based on two structured and systematic processes, involving experts on injury prevention and field hockey. As a result, the 'Warming-Up Hockey' intervention was developed, including more than 50 unique exercises available through a website and an application for smartphone/tablet. Both field hockey players and coaches were overall positive about the exercises of 'Warming-Up Hockey', but several alterations needed to be made.

\section{Necessary alterations to Warming-Up Hockey}

As a consequence of the feedback from both players and coaches during the feasibility study, two major alterations to the 'Warming-Up Hockey' were made. First, the duration of the intervention was reduced from 16 to $12 \mathrm{~min}$, being divided into three phases of $4 \mathrm{~min}$ each. Second, as time and space are very limited prior to a match, a match-specific warm-up (5-10 min) was developed. These two main alterations are likely to benefit the future use and implementation of the intervention. For both main alterations, the six experts previously involved in the development of 'Warming-Up Hockey' (step 4) were consulted. Subsequently, final texts and videos (including voiceover) were produced, and the application for smartphone/tablet and website (http://hockey. warmingupapp.nl/) was developed. The three phases and related themes of 'Warming-Up Hockey' per age category can be found in table 1 , while a sample training session of the intervention is presented in table 2. Illustrations of the application for smartphone/tablet as well as examples of exercises within the intervention are presented in figure 1.

\section{Injury prevention across team sports}

Because injuries have negative influences on sport participation and result in high costs for society, injury prevention interventions have been developed across several sports. The FIFA injury prevention programme (FIFA 11+) was developed to reduce football-related injuries. ${ }^{25}$ Divided into 3 parts and based on 15 exercises, the FIFA 11+ is a warm-up programme focusing on injury prevention among football players aged 14 and older. ${ }^{25}$ Several randomised controlled trials have evaluated the effectiveness of the programme, showing an injury reduction of $35 \%$ among female players and

Table 1 Phases and themes of the injury prevention intervention in field hockey per age category

\begin{tabular}{|c|c|c|c|c|}
\hline & $8-9$ years & $10-11$ years & $12-15$ years & $16+$ years \\
\hline Preparation phase & - Agility. & - Agility. & - Agility. & $\begin{array}{l}\text { Warm-up. } \\
\text { Sport-specific } \\
\text { activation. }\end{array}$ \\
\hline Movement skills & $\begin{array}{l}\text { Posture. } \\
\text { Flexibility. }\end{array}$ & $\begin{array}{l}\text { Stability. } \\
\text { Flexibility. }\end{array}$ & $\begin{array}{l}\text { Stability. } \\
\text { Flexibility. }\end{array}$ & $\begin{array}{l}\text { Stability lower } \\
\text { extremities. } \\
\text { Core stability. } \\
\text { - Flexibility. }\end{array}$ \\
\hline Field hockey skills & $\begin{array}{l}\text { Speed in field hockey } \\
\text { situations. } \\
\text { Strength in field } \\
\text { hockey situations. }\end{array}$ & $\begin{array}{l}\text { Speed in field hockey } \\
\text { situations. } \\
\text { Strength in field } \\
\text { hockey situations. }\end{array}$ & $\begin{array}{l}\text { Speed in field hockey } \\
\text { situations. } \\
\text { Strength in field } \\
\text { hockey situations. }\end{array}$ & $\begin{array}{l}\text { Speed in field hockey } \\
\text { situations. } \\
\text { Strength in field hockey } \\
\text { situations. }\end{array}$ \\
\hline
\end{tabular}


Table 2 Sample training of the injury prevention intervention in field hockey (in this case: week 6 for $16+$ years)

\section{Preparation phase}

Warm-up drills including dribbling (slow, fast), tripling (slow, fast), skipping (left leg, right leg, slow, fast), low knee lift (left leg, right leg, slow, fast), high knee lift (left leg, right leg, slow, fast), heel flick (left leg, right leg, slow, fast), striding out, sprint.

Simulation with hockey stick: two rows of players line up behind each other in a straight line with four cones

2 rep. 1 min. $10 \mathrm{~m}$ away from each other; players of both rows dribble with their stick to the first cone and simulate ball control; players dribble with their stick to the second cone and simulate a pass; players dribble with their stick to the third cone and simulate ball control; players dribble with their stick to the last cone and simulate a pass; players turn and dribble back to the starting point $(40 \mathrm{~m})$.

\section{Movement skills}

One leg high-far jump: players line up $2 \mathrm{~m}$ from each other with one cone $10 \mathrm{~m}$ away; players stand on their left leg with their knee slightly bent; players jump with their left leg as high and far as possible and land on their left leg (attention for a stable landing); players repeat high-far jumps over the $10 \mathrm{~m}$; players perform the same exercise on the way back with their right leg.

Core stability: players lie on their stomach on the ground with their forearms/elbows on the ground; players raise their body so that they are resting on their forearms and toes (back completely straight); players hold this position for $20 \mathrm{~s}$; players lift their left leg, hold this position for $10 \mathrm{~s}$ and return to the original position; players lift their right leg, hold this position for $10 \mathrm{~s}$ and return to the original position; players hold the original position for $20 \mathrm{~s}$.

Deep overhead squat: players line up $2 \mathrm{~m}$ from each other with their heels on their hockey sticks (alignment of feet and shoulders); players raise their arms over their head; players perform a deep squat and return to the original position.

Field hockey skills

One leg side jump and sprint: two rows of players line up behind each other in a straight line with four cones 2 min. $10 \mathrm{~m}$ away from each other; players of both rows stand face-to-face on their left leg with their knee slightly bent; players jump quickly with their left leg towards the first cone; at the first cone, players turn and sprint at maximal speed towards the third cone $(20 \mathrm{~m})$; players lower their speed until the last cone; players turn and dribble back to the starting point $(40 \mathrm{~m})$; players change sides and perform the exercise once more on their left leg; players perform the exercise twice on their right leg.

Cones run: two rows of players line up behind each other in a straight line with 20 cones 2 m away from each 2 min. other (40 m); players of both rows cover the $40 \mathrm{~m}$ by sprinting forward each time over three cones $(4 \mathrm{~m})$ and backwards between two cones $(2 \mathrm{~m})$; players turn and dribble back to the starting point (40 $\mathrm{m})$.

m, meter; min, minute; rep, repetition; s, second.

$50 \%$ among male players. $^{25}$ In the Netherlands, an integral exercise-based intervention (more than 50 exercises; age-specific and gender-specific) was developed to prevent or reduce finger/wrist, shoulder, knee and ankle injuries in recreational volleyball. ${ }^{8}$ As this intervention was found feasible by volleyball players and coaches, a randomised controlled trial has been initiated in order to evaluate its effectiveness on the occurrence of injuries among recreational adult volleyball players. ${ }^{26}$ In rugby, a recent study showed that a preventive movement control exercise programme reduced match injury outcomes among young rugby players. ${ }^{27}$ With regard to the conceptual similarities with especially the FIFA 11+, one might be confident that 'Warming-Up Hockey' will lead to the reduction of lower extremity injuries among young and adult recreational field hockey players.

\section{Future directions}

According to van Mechelen et $a l \mathrm{~s}^{28}$ 'sequence of prevention' model, the development of 'Warming-Up Hockey' should be followed by the evaluation of its effectiveness. Consequently, a prospective controlled trial has started in the Netherlands in order to establish whether 'Warming-Up Hockey' leads to injury reduction among young recreational field hockey players. In the case of empirical evidence for its effectiveness, the implementation of 'Warming-Up Hockey' in the real-world field hockey setting will be initiated. However, such an implementation should consider that our needs assessment revealed that only $45 \%$ of the field hockey coaches stated that they had sufficient knowledge about injury prevention and wanted to have a proactive role towards injury prevention. Therefore, a particular attention should be given to the education of field hockey coaches. Ideally, this implementation will be evaluated in accordance with the Reach Efficacy Adoption Implementation Maintenance (RE-AIM) framework. ${ }^{29} \mathrm{~A}$ clear understanding of the barriers and facilitators for all five RE-AIM dimensions is a prerequisite for a successful implementation and to ensure a large impact among field hockey players. The availability of the "Warming-Up Hockey' as an application for smartphone/tablet with videos might facilitate its implementation and the optimal execution of its exercises. 


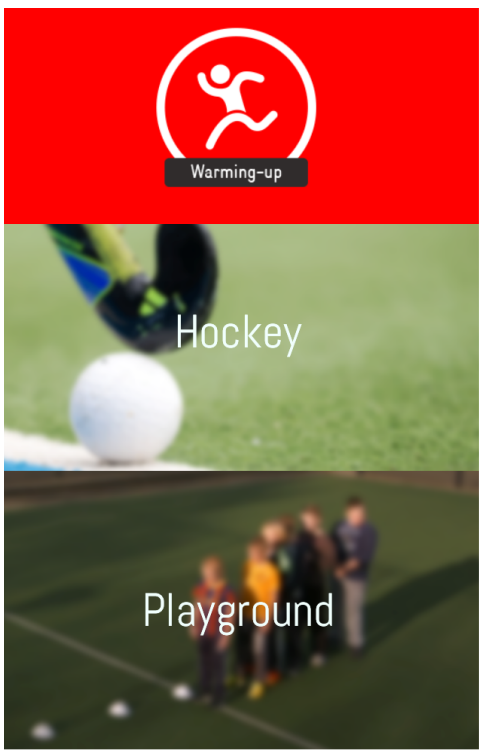

veiligheid $\rightarrow \mathrm{nl}$
Je kunt inloggen of registreren om je trainingsschema op te slaan. Zo kun je ook vanaf de website je trainingsschema openen.

\section{f $\quad$ Log in with Facebook} $\mathrm{OF}$ LOG IN / REGISTREER

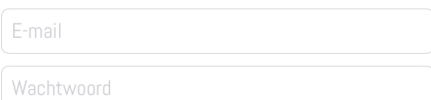

Ik ben mijn wachtwoord vergeten Log in / registreer

\section{Nu niet}

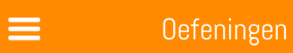

Fase 1: Voorbereiding

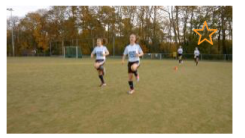

Loop-ABC

Imitatie van technieken

eugd, E-jeugd, Senioren A-jeugd, Senioren

Fase 2: Motorische vaardigheden
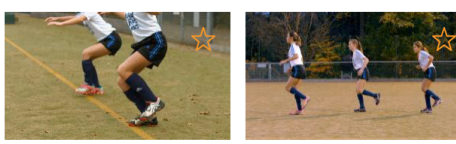

Eenbenige squat

Vierkwadrantensprong

A-jeugd, Senioren

Fase 3: Hockey vaardigheden

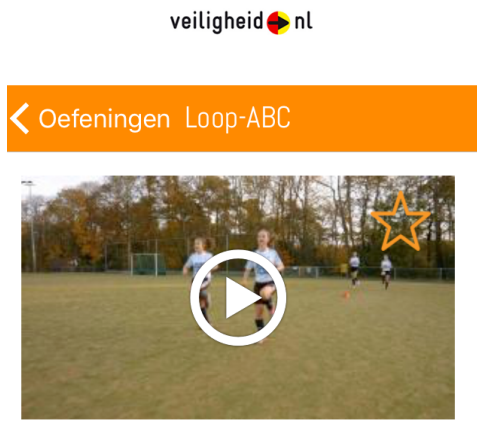

Loop-ABC

DUUR: 2 MINUTEN

DOELGRoEP: A-JEUGD, B-JEUGD, C-JEUGD, D-JEUGD, E-...

DOEL

Het soepel maken van de spieren en het verhogen van de ademhaling en de bloedsomloop. Het verbeteren van de looptechniek en een stabiele romphouding (atletische houding), terwijl de armen en benen snel bewegen.

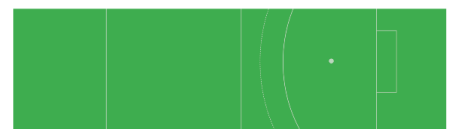

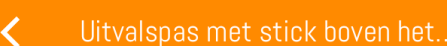

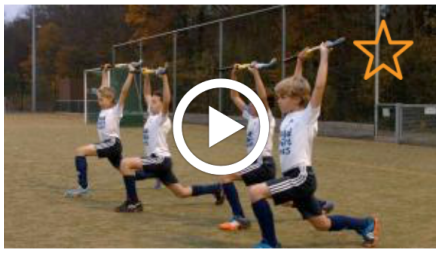

Uitvalspas met stick boven het offline ne hoofd

\section{DUUR: 2 MINUTEN MINUTEN}

DOELGROEP: A-JEUGD, SENIOREN

DOEL

Het vergroten van de flexibiliteit van de voorkant van het lichaam door middel van het dynamisch rekken van spierketens en zenuwbanen.

Daarnaast is de uitvalspas een hockeyspecifieke kracht- en stabiliteitsvorm voor de hele onderste extremiteitsketen.

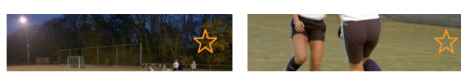

E Wedstrijd warming-up

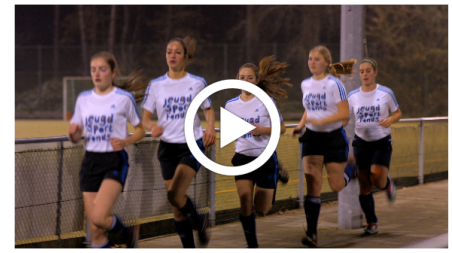

Een goede warming-up voor de wedstrijd is belangrijk. Je vindt hier een verantwoorde warming-up die je zowel binnen als buiten het veld kunt doen met spelers en keeper.

Speler
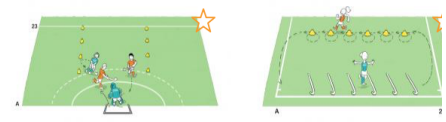

Twee tegen één met Zebra

\section{CONCLUSION}

'Warming-Up Hockey' has been developed in order to prevent or reduce the occurrence of lower extremity injuries among young and adult recreational field hockey players. The feasibility of 'Warming-Up Hockey' was positively assessed by players and coaches. Before its nationwide implementation, a study into the effectiveness of the intervention on injury reduction among field hockey players should be conducted.

Acknowledgements The authors greatly thank all field hockey and injury prevention experts involved in the development of the intervention. The authors are also thankful to all coaches and players for their participation in the feasibility study.
Contributors Both authors were responsible for the conceptualisation, preparation and performance of the study. VG was responsible for the preparation of the manuscript. VZ was responsible for the critical review of the manuscript. Both authors read and approved the final manuscript.

Funding The authors have not declared a specific grant for this research from any funding agency in the public, commercial or not-for-profit sectors.

Competing interests None declared.

Patient consent Not required.

Ethics approval Since this study did not meet the criteria for the Medical Research Involving Human Subjects Act (WM0), it did not require approval from a Dutch human ethics research committee. This study was conducted in accordance with the Declaration of Helsinki and the Personal Data Protection Act (WBP).

Provenance and peer review Not commissioned; externally peer reviewed. 
Open access This is an open access article distributed in accordance with the Creative Commons Attribution Non Commercial (CC BY-NC 4.0) license, which permits others to distribute, remix, adapt, build upon this work non-commercially, and license their derivative works on different terms, provided the original work is properly cited, appropriate credit is given, any changes made indicated, and the use is non-commercial. See: http://creativecommons.org/licenses/by-nc/4.0.

\section{REFERENCES}

1. Dutch Olympic Committee*Dutch Sports Federation (NOC*NSF), 2017. Members in dutch sport federations. https://www.nocnsf.nl/ ledentallen (accessed 17 Aug 2018).

2. Theilen TM, Mueller-Eising W, Wefers Bettink $P$, et al. Injury data of major international field hockey tournaments. $\mathrm{Br} J$ Sports Med 2016;50:657-60.

3. Dick R, Hootman JM, Agel J, et al. Descriptive epidemiology of collegiate women's field hockey injuries: national collegiate athletic association injury surveillance system, 1988-1989 through 20022003. J Athl Train 2007;42:211-20.

4. Dutch Consumer Safety Institute (VeiligheidNL), 2012. Field hockey injuries. https://www.veiligheid.nl/sportblessures/kennis/cijfers-oversportblessures (accessed 07 Jan 2017).

5. Bartholomew LK, Parcel GS, Kok G. Intervention mapping: a process for developing theory- and evidence-based health education programs. Health Educ Behav 1998;25:545-63.

6. Kok G, Gottlieb NH, Peters GJ, et al. A taxonomy of behaviour change methods: an intervention mapping approach. Health Psychol Rev 2016;10:297-312

7. Verhagen E, Voogt N, Bruinsma A, et al. A knowledge transfer scheme to bridge the gap between science and practice: an integration of existing research frameworks into a tool for practice. Br J Sports Med 2014;48:698-701.

8. Gouttebarge V, van Sluis M, Verhagen E, et al. The prevention of musculoskeletal injuries in volleyball: the systematic development of an intervention and its feasibility. Inj Epidemiol 2017;4:25.

9. Bowen DJ, Kreuter M, Spring B, et al. How we design feasibility studies. Am J Prev Med 2009;36:452-7.

10. Abernethy L, Bleakley C. Strategies to prevent injury in adolescent sport: a systematic review. Br J Sports Med 2007;41:627-38

11. Behm DG, Drinkwater EJ, Willardson JM, et al. Canadian society for exercise physiology position stand: the use of instability to train the core in athletic and nonathletic conditioning. Appl Physiol Nutr Metab 2010;35:109-12.

12. Behm D, Colado JC. The effectiveness of resistance training using unstable surfaces and devices for rehabilitation. Int J Sports Phys Ther 2012;7:226-41.

13. Gagnier JJ, Morgenstern H, Chess L. Interventions designed to prevent anterior cruciate ligament injuries in adolescents and adults: a systematic review and meta-analysis. Am J Sports Med 2013;41:1952-62.

14. Lauersen JB, Bertelsen DM, Andersen LB. The effectiveness of exercise interventions to prevent sports injuries: a systematic review and meta-analysis of randomised controlled trials. Br J Sports Med 2014;48:871-7.

15. Mandelbaum BR, Silvers HJ, Watanabe DS, et al. Effectiveness of a neuromuscular and proprioceptive training program in preventing anterior cruciate ligament injuries in female athletes: 2-year followup. Am J Sports Med 2005;33:1003-10.

16. Markovic G, Mikulic P. Neuro-musculoskeletal and performance adaptations to lower-extremity plyometric training. Sports Med 2010;40:859-95.

17. McCurdy K, Walker J, Armstrong R, et al. Relationship between selected measures of strength and hip and knee excursion during unilateral and bilateral landings in women. J Strength Cond Res 2014;28:2429-36.

18. Myer GD, Ford KR, McLean SG, et al. The effects of plyometric versus dynamic stabilization and balance training on lower extremity biomechanics. Am J Sports Med 2006;34:445-55.

19. Steffen K, Emery CA, Romiti M, et al. High adherence to a neuromuscular injury prevention programme (FIFA 11+) improves functional balance and reduces injury risk in Canadian youth female football players: a cluster randomised trial. Br J Sports Med 2013:47:794-802.

20. Ugalde V, Brockman C, Bailowitz Z, et al. Single leg squat test and its relationship to dynamic knee valgus and injury risk screening. $P m$ $R$ 2015;7:229-35.

21. Verhagen $\mathrm{E}$, van $\operatorname{der}$ Beek $\mathrm{A}$, Twisk J, et al. The effect of a proprioceptive balance board training program for the prevention of ankle sprains: a prospective controlled trial. Am J Sports Med 2004;32:1385-93.

22. Wikstrom EA, Naik S, Lodha N, et al. Balance capabilities after lateral ankle trauma and intervention: a meta-analysis. Med Sci Sports Exerc 2009;41:1287-95.

23. Yosmaoglu HB, Baltaci G, Kaya D, et al. Tracking ability, motor coordination, and functional determinants after anterior cruciate ligament reconstruction. J Sport Rehabil 2011;20:207-18.

24. Zech A, Klahn P, Hoeft J, et al. Time course and dimensions of postural control changes following neuromuscular training in youth field hockey athletes. Eur J Appl Physiol 2014;114:395-403.

25. Bizzini M, Dvorak J. FIFA 11+: an effective programme to prevent football injuries in various player groups worldwide-a narrative review. Br J Sports Med 2015;49:577-9.

26. Gouttebarge V, Zwerver J, Verhagen E. Preventing musculoskeletal injuries among recreational adult volleyball players: design of a randomised prospective controlled trial. BMC Musculoskelet Disord 2017;18:333.

27. Hislop MD, Stokes KA, Williams S, et al. Reducing musculoskeletal injury and concussion risk in schoolboy rugby players with a pre-activity movement control exercise programme: a cluster randomised controlled trial. Br J Sports Med 2017;51:1140-6.

28. van Mechelen W, Hlobil H, Kemper HC. Incidence, severity, aetiology and prevention of sports injuries. A review of concepts. Sports Med 1992;14:82-99.

29. Glasgow RE, Vogt TM, Boles SM. Evaluating the public health impact of health promotion interventions: the RE-AIM framework. Am J Public Health 1999;89:1322-7. 